\title{
Assessment of oil-producing wells by means of stimulation approach through matrix acidizing: a case study in the Azraq region
}

\author{
Mehaysen Al-Mahasneh $^{1}$ (D) . Said Al Rabadi ${ }^{1}$ (D) Hussam Khaswaneh ${ }^{1}$ (D)
}

Received: 26 March 2021 / Accepted: 3 August 2021 / Published online: 16 August 2021

(c) The Author(s) 2021

\begin{abstract}
The acidizing approach belongs to the well workover operations, where acid mixtures are initially implemented to treat damage near the wellbore area after drilling operations have been completed. Acidizing treatment is characterized by removal of fine particles and debris from the porous media of the damaged zone, hence leading to improve oil production from wells. This study evaluates the assessment of the acidizing treatment in vertical oil-producing wells. Gradually, the damage formation was reduced and then eliminated, and to a great extent, was compensated with the better performance of oil production from reservoirs. Target candidate wells were enriched by environmentally friendly additives and special chemicals, in predefined amounts, to achieve enhanced oil production rates from wells. A semi-analytical model was formulated for extrapolating the skin magnitude, depending on the damage formation's permeability parameter as well as on the physical characteristics and reservoir depth. The figures of skin magnitude for all target wells were decreased, and oil production rates were enhanced after performing the matrix acidizing process. These findings are valid for diverse geological settings of different formations, as all treated intervals within the investigated wells have shown an objective response to the matrix acidizing approach. Eventually, productivity rates are imperative to increase potential economic outcomes.
\end{abstract}

Keywords Matrix acidizing $\cdot$ Performance $\cdot$ Damage radius $\cdot$ Productivity index $\cdot$ Skin magnitude

\section{Introduction}

Two major well-acidizing approaches are often applicable for curing damage around the wellbore, namely, matrix acidizing and acid fracturing (Civan 2007; Bale et al. 2010; Morsy et al. 2013; Liang et al. 2017; Leung and Mahmud 2019). The matrix acidizing process is a chemical stimulation technique that involves the injection of acid mixtures below the fracture pressures of rocks near the wellbore. Its purpose is dissolving sediments to reinforce rock permeability and the establishment of a clean zone within the reservoir, thus eliminating the restrictions for oil flux into the wellbore zone. Commonly, matrix acidizing is applied in case of tighter carbonate and sandstone formations; it is recommended in industry to utilize acids with mass concentrations, in the range of $10-15 \%$, while acid fracturing is implemented in case of carbonate formations (Bale et al.

Said Al Rabadi

said.alrabadi@bau.edu.jo

1 Chemical Engineering Department, Al-Balqa Applied University, Huson 21510, Jordan
2010; Li et al. 2015; Liang et al. 2017; Kolin et al. and Kurevija et al. 2018) with relatively higher acid mass concentrations, in the range of $20-30 \%$. This method involves acid injection to create channels or so-called wormholes, as the resulting rock fractures, under pressure from the hydrocarbons, might immigrate through. It is noteworthy that a third method-acid washing-could be required in special applications including high water-saturated sediments (Mahasneh et al. 2018; Zhang et al. 2020). Basically, the two above-mentioned methods are generally characterized with respect to injection rates and fracture pressures. Rabbani et al. (2018) have revealed that the reservoir's physical characteristics, such as rock permeability, are criteria for choosing the applicable acidizing methods. It is vital to extensively consider the damage mechanisms when designing a matrix treatment, such as dissolving calcites, quartz, or clay minerals, which alter the reservoir's behavior toward the acids (Kolin et al. and Kurvijc et al. 2018). Generally, the hydrochloric $(\mathrm{HCl})$ acid is substantial in enhancing oil production; it is advantageous in eliminating dolomite and limestone materials from reservoirs and is greatly utilized in carbonate acidizing (Chang et al. 2008; Khalil et al. 2021).

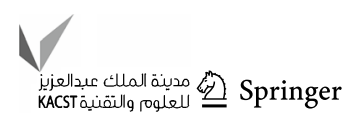


In some applications, mixtures of $\mathrm{HCl}$ and hydrofluoric acids (HF) are implemented, which boost the dissolving of sandstones and other silicate content in the reservoir rocks (Tang et al. 2002; Thomas et al. 2002; Patton et al. 2003; Shafiq and Mahmud 2016; Rabbani et al. 2018). The technical objectives of well stimulation are to eliminate or bypass the formation damage, therefore reducing the debris production, and the gravel packs are eventually cleaned up (Ifeanyi et al. 2015; Ugbenyen 2011; Wilfred and Umeleuma 2015).

Despite being a common procedure, only few studies have investigated the effect of matrix acidizing on the physical characteristics and recovery factors in oil reservoirs. The effect of $\mathrm{HCl}$ treatment on porosity, spontaneous inhibition, and formation distribution for investigated wells of formations was demonstrated by Morsy et al. (2013); their evaluation was relatively complex and was restricted to the application of special parameters such as formations' decipherability and crack distributions. In contrast, the investigations of Wilfred and Umeleuma (2015) have revealed the role of the mixed acids in the executed acidizing process; on the other hand, caution should be taken in figuring out the exact formation's mineralogy, water saturation in the reservoir, and only limited additives should be introduced for their investigated cases of oil fields, in order to avoid side effects such as emulsion formation. The particulate materials that are plugging the pore structure will be reducing the rock permeability extensively. In the studies of Li et al. (2015), Wilfred and Umeleuma (2015), and Yancheng et al. (2017), the effect of rock type, acidizing additives, and other experimental parameters were investigated on crack distributions for reservoir's rocks. Particularly, their experimental procedures widely vary and produce very different results of the treatment processes due to rock impurities. Similar findings were highlighted in the studies of Qteishat et al. (2018) and Al-Mahasneh (2020); it has been stated that the reactivity of reservoir rock toward acid stimulation is influenced, to a great extent, by the existence of mineral impurities within the rocks, such as clay. Existing of clay impurities in calcite rock act as sealing layer, which are, consequently, considered to be disadvantageous in the oil production process. Besides acids, the inclusion of acidizing additives, such as polymers and corrosion inhibitors, has been shown to significantly affect the mechanism with which the acid reacts to the reservoir's rock. While in the studies of Garrouch and Jennings (2017) and Khalil et al. (2021), matrix acidizing with special additives of carbonate reservoirs was performed, through deducing the impact of this stimulation technique on the wells' technical characteristics and the performance of chosen reservoirs before and after acidizing jobs. The wells' technical characteristics include the flow efficiency, productivity indices, and stimulation gain, which have shown a positive response toward acid stimulation. Whereas, models applying reservoir characteristics are highly recommended and merit further investigations due to economic and environmental impacts for acid stimulations of oil wells, where acids are primarily used to eliminate the impeded damage around the wellbore.

Principally, formation damage, or so-called skin magnitude, is referred to a phenomenon that reduces the oil production of a reservoir; it is to be focused on it as the stimulation mechanism for the current investigations. The target area of this study is located in the northeastern region of Azraq/Jordan. Four oil wells in the target region, characterized with diverse physical properties and formation intervals, were investigated to obtain comprehensive information and relevant outcomes for future investments of this rural area. Basically, the geological column cross litho-stratigraphic images of Azraq region and the formation intervals of Shueib and Hummer are depicted in Al-Mahasneh (2020). These figures represent a promising and thick stratigraphic section, which is primarily composed of various sediments such as carbonate, limestone, and shale sediments, ranging from the early Paleozoic to the late Paleocene era, with an average vertical distance in excess of $3000 \mathrm{~m}$ from surface. The combined effect of the tectonic events led to an intense structuring of the Cenomanian and Turonian formations of the Azraq region, where the target layers of Shueib and Hummer formation are spatially located and are separated with the isolated un-permeable zones. According to previous surveys performed by official authorities in this region, the target wells contain superimposed layers of multiple hydrocarbon fractions with considerable estimated amounts, which merit further investments. $\mathrm{HCl}$ has significant advantages in acidizing treatment of limestone and dolomite layers, following the studies of Chang et al. (2008), Shafiq and Mahmud (2016), Leong and Mahmud (2019), and Khalil et al. (2021). According to the chemical composition of Shueib and Hummar formation, the corresponding reactions of these structures with $\mathrm{HCl}$ acid could be described as follows:

$\begin{array}{ccc}\text { Formation } & \text { Layer } & \text { Chemical Reaction } \\ \text { Hummar Limestone } \mathrm{CaCo}_{3}+2 \mathrm{HCL} \rightarrow \mathrm{CaCl}_{2}+\mathrm{H}_{2} \mathrm{O}+\mathrm{CO}_{2}\end{array}$

Sheuib Dolomite $\mathrm{CaMg}\left(\mathrm{CO}_{3}\right)_{2}+4 \mathrm{HCl}$

$\rightarrow \mathrm{CaCl}_{2}+\mathrm{MgCl}_{2}+2 \mathrm{H}_{2} \mathrm{O}+2 \mathrm{CO}_{2}$

In general, it could be noticed that aqueous solutions are formed from these chemical reactions. The actual characteristics regarding the water saturation enhance the prediction of remaining oil saturation in the target wells and could achieve reasonable oil recovery (Ahmed 2010; Zhang et al. 2020). With respect to the reaction of dolomite with $\mathrm{HCl}$ acid, the stoichiometric ratio of calcium to magnesium elements must be considered as not constant (Chang et al. 2008; Tiab and Donaldson 2016). Hence, the outcome is a mixture 
of precipitated salt as calcium chloride and the soluble magnesium chloride in the aqueous solution. Following the relevant findings, the evaluation of the conducted operations approved that matrix acidizing is the best stimulation technique below the fracture pressure of the reservoir's rocks, which had invariably increased the oil productivity. On the other hand, it is recommended that the formation's structure should be extensively studied, as cost-factored and environmentally cautious additives could be pumped with the acid mixtures into the wellbore, in order to monitor corrosion of pipes and avoid reverse effects due to emulsion formation. In this context, the acidizing process of an oil-producing well could be categorized as effective when basically, the production rates would increase in comparison with respect to un-treated well candidates. In this study, a nonlinear model is presented to predict the formation damage and to evaluate the acid treatment process in the target vertical oil wells, under the influence of skin magnitudes. Through a set of crucial physical parameters, the oil well productivity was identified.

This effect is generally known as the "Wellbore Damage Effect" or so-called Skin Magnitude. It might extend to several meters from the wellbore (Soare and Bratu 1987; Civan 2007), leading to a decrease in well oil production. In the acidizing treatment process, special acid mixtures are used to eliminate the damage near the wellbore, with the undamaged boundary radius $\left(r_{\mathrm{d}}\right)$, in majority kinds of wells, which consist particularly from sandstone, limestone, or dolomite layers, that could provide an increase in well productivity as a consequence. Figure 1 depicts the proposed model for skin magnitude. Hydrostatic pressure in the extension with the undamaged boundary radius $\left(r_{\mathrm{e}}\right)$ and the permeability $\left(k_{\mathrm{e}}\right)$ is reading higher values than the well flow pressure $\left(P_{\mathrm{wf}}\right)$ at the same hydrostatic vertical height in the wellbore zone; hence, a skin pressure drop $\left(\Delta P_{\text {skin }}\right)$ is created. This pressure drop is the driving force for oil immigration into the wellbore zone and is responsible for enhancing the oil production rates after cleaning up of the gravel packs form the wellbore zone; the damage ratio (DR) employs the ratio of drawdown pressure variation between undamaged zones, the oil production rate, and the reservoir's physical characteristics. According to the fluid mechanic concepts, hydrostatic pressure $\left(P_{\mathrm{s}}\right)$ is calculated by the hydrostatic height $(z)$ oil column in the well, multiplied by the specific gravity $(\gamma)$ of the well fluid. According to outcomes of Horner plot, the well flow pressure, skin pressure drop, and well (DR) are estimated (Tang et al. 2002; Civan 2007; Ahmed 2010; Tiab and Donaldson 2016):

$P_{\mathrm{S}}=z \cdot \gamma$

$P_{\mathrm{wf}}=P_{1 \mathrm{hr}}-m \cdot \log \left(\frac{t+\Delta t}{\Delta t}\right)$

$\Delta P_{\text {Skin }}=P_{\mathrm{s}}-P_{\mathrm{wf}}-\left(\frac{P_{\mathrm{s}}-P_{\mathrm{wf}}}{\mathrm{DR}}\right)$

$\mathrm{DR}=\left[\frac{P_{s}-P_{\mathrm{wf}}}{m \cdot \log \left(\frac{k_{\mathrm{d}} \cdot T_{\mathrm{r}}}{Q \cdot \mu \cdot C_{\mathrm{r}} \cdot r_{\mathrm{w}}^{2}}-2.85\right)}\right]$ and $T_{\mathrm{r}}=\frac{k_{\mathrm{d}} \cdot H}{\mu}=\frac{162.6 \cdot Q \cdot B}{m}$,

where $(m)$ is the pressure variation with the hydrostatic vertical distance, or the so-called pressure gradient, with units of [bar/cycle] and could be evaluated from Horner data of the target reservoir, as was stated in Kolin et al. and Kurevija et al. (2018); $(B)$ is the oil formation volume factor, defined as the ratio the reservoir's oil volume at the prevailing conditions (temperature, pressure, water saturation) with respect to standard conditions at the surface; $(t)$ is the time interval; $\left(c_{\mathrm{t}}\right)$ is total compressibility; $(H)$ is formation thickness; $\left(k_{\mathrm{d}}\right)$

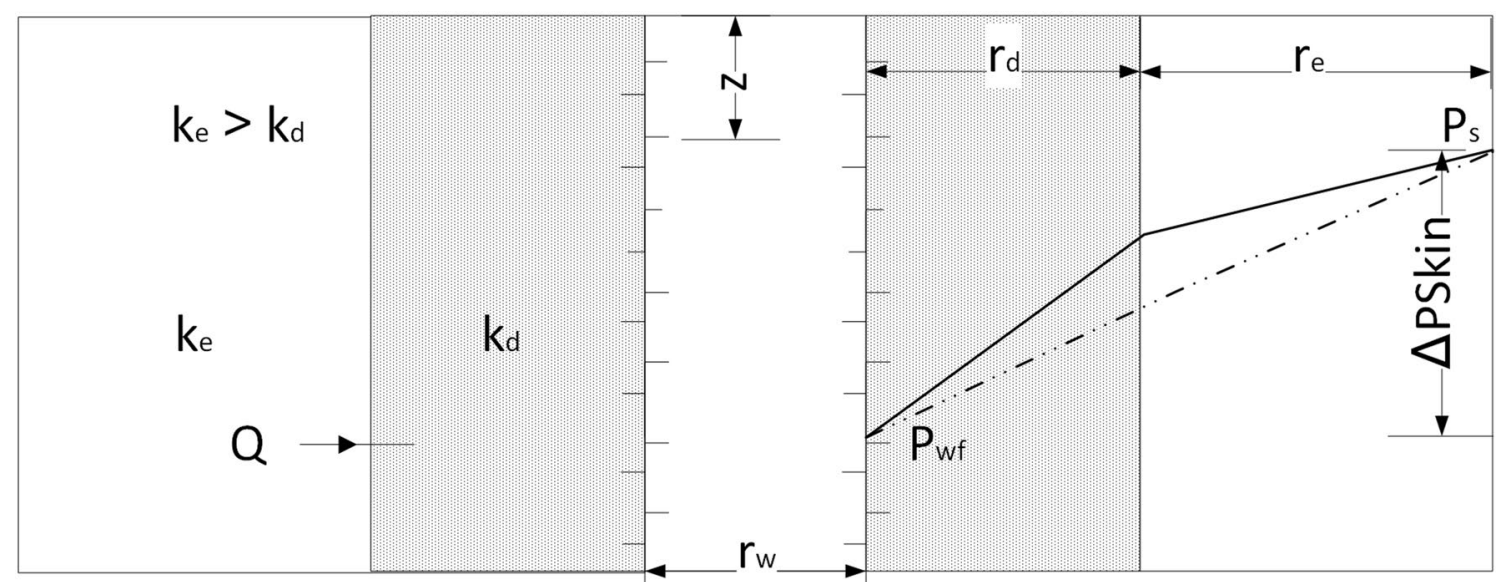

Fig. 1 Proposal model for well Skin Magnitude 
is the permeability of damaged zone, $(\mu)$ is the oil dynamic viscosity, $\left(P_{1 \mathrm{hr}}\right)$ is the interpretation of pressure in Horner plot after $1 \mathrm{~h}$ of well shut-in; $(Q)$ is the production rate; $\left(r_{\mathrm{w}}\right)$ is wellbore radius; and $\left(T_{\mathrm{r}}\right)$ is the well transmissibility that is utilized as a measure of the connectivity parameter of the formation corrected for the viscosity of the flowing hydrocarbon, as was stated by Earlougher Jr. (1977), Soare and Bratu (1987), Ifeanyi et al. (2015), Tiab and Donaldson (2016), and Chukwuma and Clifford (2019). Skin pressure drop, presented in Eq. (5), is calculated based on drawdown pressure as well the (DR) parameter, which is mathematically expressed by Eq. (6). By applying simple Bernoulli equation on well flow region and undamaged zone at an identical hydrostatic height in the reservoir, we get

$\frac{P_{\mathrm{wf}}}{\gamma}+z_{\mathrm{wf}}+\frac{V_{\mathrm{wf}}^{2}}{2 \cdot g}+h_{\mathrm{L}}=\frac{P_{\mathrm{s}}}{\gamma}+z_{\mathrm{s}}+\frac{V_{\mathrm{s}}^{2}}{2 \cdot g}$

where $\left(h_{\mathrm{L}}\right)$ term is a discrete form of oil flow losses in wormholes hydraulics within wellbore zone. Based on the findings of Tang et al. (2002) and Ahmed (2010), the wormholes are extended beyond the damaged zone to achieve a reasonable oil productivity from vertical wells. Basically, the oil flow losses in wormholes hydraulics are small and negligible for oil fields with mainly vertical orientation. Comparing with vertical oil well, oil flow losses are more important for horizontal oil wells (Yuan et al. 2015). Fluid in the undamaged zone is considered under stagnation conditions; Eq. (7) could be simplified and the well flow velocity is estimated as:

$V_{\mathrm{wf}}=C_{1} \cdot \sqrt{\left(\frac{P_{\mathrm{s}}-P_{\mathrm{wf}}}{\rho}\right)}$

The constant $\left(C_{1}\right)$ stands for a dimensionless conversion factor, and $(\rho)$ is the oil mass density. Equation (8) implies the conversion of hydrostatic potential into kinetics of oil toward the wellbore zone. According to well continuity approach, the volumetric oil production rate could be combined with well flow velocity and the extension area containing oil, to figure out the reservoir's undamaged boundary radius:

$$
r_{\mathrm{e}}=\sqrt{\frac{Q}{\pi \cdot V_{\mathrm{wf}}}}
$$

$r_{\mathrm{d}}=r_{\mathrm{w}} \cdot(1+\exp (S))$

Based on the findings of Soare and Bratu (1987) and Civan (2007), the $\left(r_{\mathrm{d}}\right)$ could be properly estimated by an empirical equation, which is mathematically expressed in Eq. (10) as a function of the wellbore radius and skin magnitude (S). In relevant studies of Earlougher Jr. (1977), Soare and Bratu (1987), Patton et al. (2003), Morsy et al. (2013), El-Naggar et al. (2014), Ifeanyi et al. (2015), Tiab and Donaldson (2016), Yancheng et al. (2017), Chukwuma and Clifford (2019), and Zhang et al. (2020), (S) has the values between $(-7)$ to few hundreds in positive domain. Accordingly, positive skin magnitudes increase the estimated $\left(r_{\mathrm{d}}\right)$, which physically mean a poor connection is established between the reservoir and the wellbore zone. While negative skin magnitudes for oil wells are due to established partial penetrations, which are normally characterized with considerable oil production rates. Earlier studies by Kolin et al. and Kurevija et al. 2018 have stated that skin magnitude could be an outcome of performed Horner plot tests of the target wells, but these outcomes are suffering of significant inaccuracy and should be subject to further confirmation by comparing them with model expectations. In this domain, a model for $(S)$, applying realistic configurations of formation and well characteristics, is required to properly predict the formation damage, hence to comprehensively judge the well performance toward the matrix acidizing approach. In the above reviewed literature, relevant well features such as flow efficiency (FE), productivity index (PI), damage factor (DF), and stimulation ratio (SR), based on productivity indices and flow rates, and stimulation gain (SG), are stipulated for the evaluation of the well performance toward the matrix acidizing approach. Analog to Eq. (5), the dimensionless flow efficiency is mathematically re-correlated, to introduce the effect of drawdown pressure variation in the rock matrix due to formation damage. In case of damaged wells, (FE) is smaller than one. When no skin pressure drop is established, essentially an ideal (FE) is attained, while (FE) greater than unity is achieved in case of stimulated wells. Whereas the (DF) is a dimensionless quantity given as a correlation of (FE), which describes substantive for evaluating the fractional percentage of oil production performance of the undamaged zones of the formation around the wellbore:

$\mathrm{FE}=\frac{P_{\mathrm{s}}-P_{\mathrm{wf}}-\Delta P_{\mathrm{Skin}}}{P_{\mathrm{s}}-P_{\mathrm{wf}}}$

$\mathrm{DF}=1-\mathrm{FE}$

In this context, the (PI) is commonly a relevant measured property of the well potential or ability to produce oil from reservoir. It is defined as the ratio of the stabilized production rate to drawdown pressure variation within well; its SI units are typically expressed as $\left[\mathrm{m}^{3} /\right.$ bar. d]. In other words, (PI) intellectually implies a significant evaluation of the stimulation process, when formation damages are treated by means of the acidizing approach:

$\mathrm{PI}=\frac{Q}{P_{\mathrm{s}}-P_{\mathrm{wf}}}$ 
However, (SR) is calculated by the ratio of the (PI) post to that of the pre-acidizing approach: Eq. (14), where $\left(\mathrm{PI}_{d}\right)$ and $\left(\mathrm{PI}_{\mathrm{o}}\right)$ are the post- and pre-acidizing (PIs), respectively. In the absence of well flow pressures, the (SR) is determined based on the oil flow rates: Eq. (15), for a constant drawdown pressure before and after the stimulation, where $\left(Q_{\mathrm{d}}\right)$ and $\left(Q_{\mathrm{o}}\right)$ are the post- and pre-acidizing oil flow rates, respectively:

$\mathrm{SR}=\frac{P I_{d}}{P I_{o}}$

$\mathrm{SR}=\frac{Q_{\mathrm{d}}}{Q_{\mathrm{o}}}$

whereas, the (SG) mathematically implies the established flow difference between the post- and the pre-job's production rates. Here, the pre-job flow rate indicates the oil production rate, obtained during a predefined time period, before the acidizing approach was executed, while the postjob rate is attained after the acidizing approach's execution. A successful stimulation approach would lead inherently to an enhancement in oil production rates from well reservoir:

$\mathrm{SG}=Q_{\mathrm{d}}-Q_{\mathrm{o}}$

According to the literature of Earlougher (1977), Wilfred and Umeleeuma (2015), and Yancheng et al. (2017), for null oil production rate after stimulation process has been being performed, the pre-acidizing production rate is assumed to be un-changeable; hence, no (SG) is achieved. Drawdown pressure difference across the damaged boundary, foreseen as the driving force for the oil outflow through the damaged formation into the wellbore, is correlated in Eq. (5) as a function of formation (DR). On the ground, formation damage can as well be attributable to oil-matrix compatibilities, due to the oil mechanics within porous media of well matrix. As a consequence, it is imperative that skin magnitude modeling must be comprehensive for oil-matrix compatibilities and the boundary limitations that are crucial for the evaluation of the acidizing treatment process, as was stated by Leong and Mahmud (2019). Based on above-mentioned findings and on the combination of Eqs. (5), (6), and (8), which leads to general skin magnitude modeling, a detailed model for the estimation of skin magnitude is derived in the case of vertical oil wells with carbonate and limestone matrices:

$S=\frac{\Delta P_{\text {Skin }}}{m}-B \cdot \log \left[\frac{0.1246 \cdot k_{\mathrm{d}} \cdot H}{\phi \cdot \mu \cdot r_{\mathrm{w}}^{2}} \cdot \sqrt{\frac{P_{\mathrm{s}}^{2}-P_{\mathrm{wf}}^{2}}{z}}\right]$,

where $\Phi$ is the porosity of rock matrix. Principally, the proposed model is a combination of the well characteristics, fluid physical properties, skin pressure drop, drawdown pressure difference, and hydrostatic height from surface; it is valid for diverse formations of reservoir structures. In specific, the proposed model consists of two major terms for skin magnitude estimation: the oil mechanics and reservoir characteristics and the vertical depth within the oil reservoir. As noticed from Eq. (17), acidizing matrix is essential and the reservoir characteristics are prerequisite for the implementation of this proposed modeling. The constant parameter $(0.1246)$ has typical SI-units expressed as $\left[\mathrm{s} / \mathrm{m}^{1 / 2}\right]$. The wellbore connectivity parameter $\left(k_{\mathrm{d}} \cdot H\right)$ is an indication of the oil well productivity from the reservoir; this is consistent with the findings in the literature of Earlougher Jr. (1977), Soare and Bratu (1987), Ifeanyi et al. (2015), Tiab and Donaldson (2016), and Chukwuma and Clifford (2019). The performance of the proposed model will be examined with challenging reference models in relevant studies (Patton et al. 2003; Morsy et al. 2013; El-Naggar et al. 2014; Yancheng et al. 2017; Chukwuma and Clifford 2019; Zhang et al. 2020). Due to its applicability in evaluation of well performance, the "Conventional Transient Test Skin Model" is considered as a reference model for estimation of skin magnitude. Eventually, it influences the reservoir deliverability, and to a great extent, it implies a comparable evaluation of the well candidates. This model is a correlation of the available data for damaged zone's permeability, reservoir parameters, as well pressure build-up figures; it is stated as:

$S=1.1513 \cdot\left[\frac{P_{1 \mathrm{hr}}-P_{\mathrm{wf}}}{m}-\log \left(\frac{k_{\mathrm{d}}}{\phi \cdot \mu \cdot c_{\mathrm{t}} \cdot r_{\mathrm{w}}^{2}}\right)+3.2275\right]$

Correspondingly, the values of skin magnitude with a figure greater than zero (positive) mean that a flow restriction exists between the well and the reservoir; meanwhile, a poor connection is established between wellbore zone and the reservoir. Oil reservoirs with objective response to the matrix acidizing approach-their skin magnitude could be reduced due to the acidizing approach-eventually boost the relevant oil production rates. On the other hand, considering the case of stimulated values of skin magnitude lower than zero (negative), the oil flow circumstances are potentially improved. Whereas, skin magnitude figures equal to zero mean the existence of neutral circumstances for oil production from the reservoir. In the current study, the field data will be collected from target oil wells and eventually analyzed. The relevant well characteristics, necessary for assessment of vertical oil-producing wells, must be determined. Syncretism of wells performance before and after acid treatment would accentuate 
promising opportunities of commercial investments in target oil-producing wells in the Azraq region.

\section{Methodology}

The oil field data for the matrix acidizing approach of oilproducing target wells in Azraq region were collected. Solutions of chemical agents, additives, and acid mixtures were prepared. Specific additives and chemical agents were introduced as protective measures to lower the environment impacts. Acid additives, normally implemented in practice, were environmental were friendly and included corrosion inhibitors, anti-sludge agents, surfactants, chelating agents, fluid loss control agents, and diverting of bridging agents. The experimental procedure was performed in the following consequences: the chemical agents and the acid additives were prepared according to predefined quantities and were mixed with the $\mathrm{HCl}$ solutions in special tanks. The tanks were connected to the main well inflow, and then, the prepared amounts of the acid solutions were completely pumped into the wellbore; after that, the pump was shut down, and the main well inlet pipe was closed. A reaction time interval was allowed of about 30-45 min, to ensure enough interaction between added chemicals and the rocks' matrix; correspondingly, the reservoir' oil production was established. After the main well outflow pipe was open, the effluents mainly including oil, spent acids, and aqueous phase with mud and fine particle were pushed out of the well. Since the produced oil is the interesting effluent, its production rates were recorded. Upon completion of the matrix acidizing approach, Amerada tools and electrical logging tests, which are normally implemented in exploration of hydrocarbon-containing reservoirs, were conducted for the target oil wells. Finally, the collected field data, including wells' build-up pressure and reservoir physical characteristics, were subject for further assessment of the reservoir parameters.

\section{Result and discussion}

The electrical cross-sectional logging plots are depicted in Figs. 2 and 3, for the target well candidates in Shueib and Hummar formations, respectively. Based on analytical results of more than 50 samples taken from target reservoir intervals, Shueib formation is found in a vertical interval of 2871-2898 $\mathrm{m}$ from surface. This formation is characterized with dolomite whitish-brown to brown, slightly to medium hard, porous, and saccharide crystals filled with oil. The porosity of the reservoir rock has an average of $13 \%$ and an average water saturation of $17.9 \%$; these findings are consistent with those of Qteishat et al. (2018) and Al-Mahasneh (2020). Their results have indicated that this reservoir has more likely a moderate heterogeneity in permeability and is characterized with the natural fractures within rock matrix. For the deep layer, Hummer formation is located within the vertical interval of 2912-2938 m from surface. This layer is structured with whitish-beige limestone layer, slightly medium to hard, porous, and vuggy crystals filled with oil fractions. Comparing to Shueib formation, Hummar has a relatively lower porosity of $11.5 \%$ and a higher water saturation of $20 \%$. However, dolomite has higher porosity than that of limestone. In general, dolomite carbonates have higher production of hydrocarbon than limestone reservoirs (Patton et al. 2003; Bale et al. 2010; Shafiq and Mahmud 2016; Tiab and Donaldson 2016; Rabbani et al. 2018; Yancheng et al. 2017). Accordingly, reservoirs with a permeability greater
Fig. 2 Electrical cross-sectional logging for the Shueib formation, well candidates $S 1$ and $S 2$

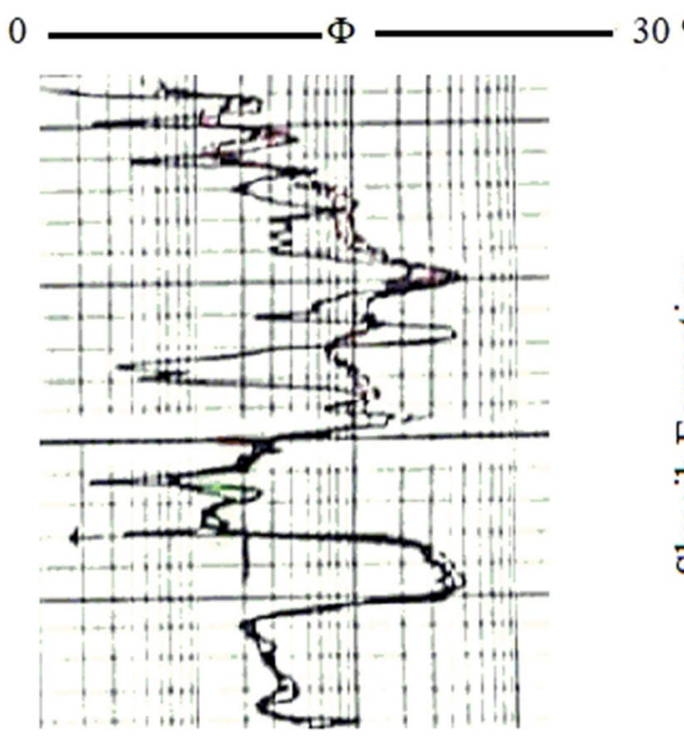
$30 \%$
Well
Candidate

S2

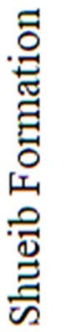

Layer
Depth [m]

$2871-2882$

S1 
Fig. 3 Electrical cross-sectional logging for the Hummar formation, well candidates $H 1$ and $H 2$

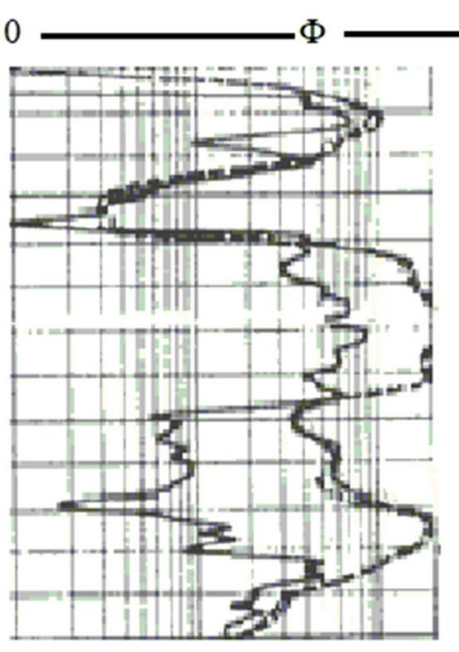

$\begin{array}{cc}\text { Well } & \text { Layer } \\ \text { Candidate } & \text { Depth }[\mathrm{m}]\end{array}$

$\mathrm{H} 2$

$2912.5-2919.5$

$\mathrm{H} 1$ saturation with respect to Shueib. This finding was inherently confirmed by Khalil et al. (2021) in relevant investigations. More focus should be drawn on diverting agent that was needed only in the second acidizing trial for the H2 target well. Meanwhile, added water amounts during the acidizing approach, specifically in Hummar formation, in turn, are consistent with reservoir's water saturation value. It is worthy to mention that an additional acidizing job for $\mathrm{H} 2$ well candidate was scheduled for a second trial, in order to obtain reasonable oil production rates. The addition of acetic acid, aqueous diverting, inhibitor, and surfactant agents to $\mathrm{HCl}$ mixtures would enhance oil productivity from the target well to a large extent, while the chelating agent would prohibit iron corrosion of the pipe material. However, side effects could be foreseen after certain time intervals of performing acidizing jobs; as a consequence, pre- and overflush oils mixtures were added. In special cases of well stimulation after which the wells were required to be flushed and
Table 1 Chemical mixture of additives and acidizing jobs for the selected well candidates

\begin{tabular}{|c|c|c|c|c|c|}
\hline \multirow{3}{*}{$\begin{array}{l}\text { Formation } \\
\text { Depth }[\mathrm{m}] \\
\text { Chemical agent Acid job }\left[\mathrm{m}^{3}\right]\end{array}$} & \multirow{3}{*}{$\begin{array}{l}\text { Hummar } \\
2912.3-2919.5 \\
\text { H1 }\end{array}$} & \multirow{3}{*}{$\begin{array}{l}\text { Shueib } \\
2889-2898 \\
\text { S1 }\end{array}$} & \multirow{2}{*}{\multicolumn{2}{|c|}{$\frac{\text { Hummar }}{2931-2938.5}$}} & \multirow{3}{*}{$\begin{array}{l}\text { Sheuib } \\
2871-2882 \\
\text { S2 }\end{array}$} \\
\hline & & & & & \\
\hline & & & $\mathrm{H} 2.1^{\mathrm{a}}$ & $\mathrm{H} 2.2^{\mathrm{a}}$ & \\
\hline HCL $15 \%$ & 6.38 & 13.0 & 10.0 & 15.0 & 12.0 \\
\hline Acetic acid & - & 0.18 & - & 0.08 & 0.02 \\
\hline Diverting agent & - & - & - & 0.95 & - \\
\hline Water & 3.4 & 6.8 & 5.35 & 8.0 & 6.7 \\
\hline Inhibitor & 0.06 & 0.12 & 0.08 & 0.15 & 0.12 \\
\hline Surfactant & 0.06 & 0.09 & 0.09 & 0.08 & 0.08 \\
\hline Chelating agent & 0.07 & 0.14 & 0.11 & 0.27 & 0.15 \\
\hline Pre flush oil with special chemicals & 6.35 & 6.5 & 2.38 & - & 2.86 \\
\hline Over flush oil with special chemical & 4.92 & 6.5 & 10.0 & 10.0 & 7.15 \\
\hline
\end{tabular}

${ }^{\mathrm{a}} \mathrm{H} 2.1$ and $\mathrm{H} 2.2$ imply first and second acidizing trials for well candidate $\mathrm{H} 2$ 
treated with chemical agents, the stimulation process could contribute, to some extent, in altering the physical properties of the reservoir's structure such as porosity and permeability.

The outcomes obtained from Amerada tools are implemented in the assessment of the oil-producing reservoirs. As an illustration, Fig. 4 shows the depth from surface as a function of the static pressure survey for well candidate H1 in Hummar formation. From the analysis of this survey, the fact to be confirmed is that the well has fluid, where it was found in a layer below the depth of $2912 \mathrm{~m}$ from the surface. An average static pressure gradient with respect to depth is obtained to be $0.092 \mathrm{bar} / \mathrm{m}$. This value is consistent with the conventional figure for pressure gradient with depth for oil reservoirs (Patton et al.; 2003; Civan 2007; Chang et al. 2008; Bale et al. 2010), which ensures that the fluid in the corresponding well candidate is a liquid hydrocarbon and not water. For conventional reservoirs with water content, it worth mentioning that the normal value for static pressure gradient with depth is about $0.101 \mathrm{bar} / \mathrm{m}$. Below the well depth of $2,938.5 \mathrm{~m}$ from surface, no variation of well static pressure is observed, which implies an establishment of a steady state depth in oil reservoir; this means that no hydrocarbon layers are to be expected.

Meanwhile, Horner data are a supportive source to indicate the head pressure survey for the assessment of oilproducing reservoirs. Horner analysis is presented for well candidate $\mathrm{H} 1$ such that the well head pressure (ordinate) is a variable with the Horner time interval (abscissa), as shown in Fig. 5. Down-trending Horner plot is obtained for well $\mathrm{H} 1$ as time interval increases, which could be attributed due to the presence of well interference even phase separation that enhances fluid mobility or due to change in the formation's porosity or permeability (Kolin et al. and Kurevija et al. 2018). The second explanation is extendly confirmed by the outcomes of attained semi-log straight line, for variation of well head pressure with respect to time interval in Horner plot, with a slope of $0.7 \mathrm{bar} / \mathrm{cycle}$. It is also found that the well flow and interpretation pressures after $1 \mathrm{~h}$ of well shut-in were estimated to be 248 and 260 bar for target well candidate. In praxis, reading relatively higher figure for the well head pressure normally means that the well is in active state with respect to oil production.

Based on the outcomes of Amerada tools and the data analysis of the Horner plot for the target well candidates, the estimated parameters for reservoir's characteristics are summarized in Table 2, for both the Hummar and Shueib reservoirs pre- and post-matrix acidizing, respectively. The outcomes were utilized for further calculations of well properties and sequential assessment of the well performance following the acidizing treatment. The oil field data of the target oil wells are showing a variation in hydrostatic, well flow, and interpretation pressures, whereas the high-pressure figures ensure that the oil wells are in an active state. The estimated values for the Horner plot slope of each relevant target well tend to increase upon completion of the matrix approach, which is consistent with the findings of the literature of Ugbenyen et al. (2011), Tiab and Donaldson (2016), Kolin et al. and Kurevija et al. (2018). For the investigated well candidates, the 1-h interpretation pressure presents a higher value than the well flow pressure; for example, it was found that the 1-h interpretation pressure was obtained with the value of

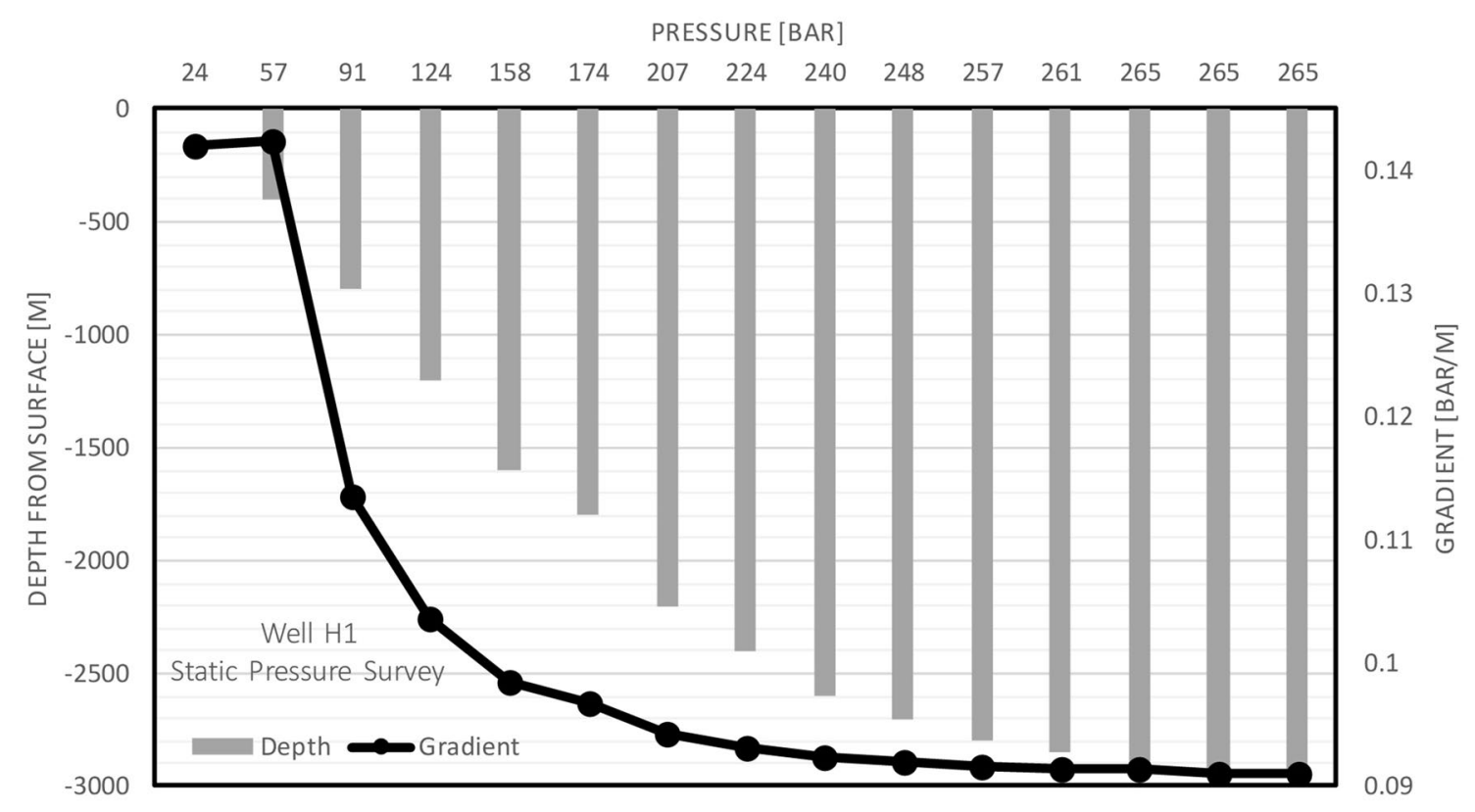

Fig. 4 Static pressure survey for well candidate $H 1$ in Hummar formation by Amerada tools

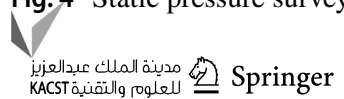




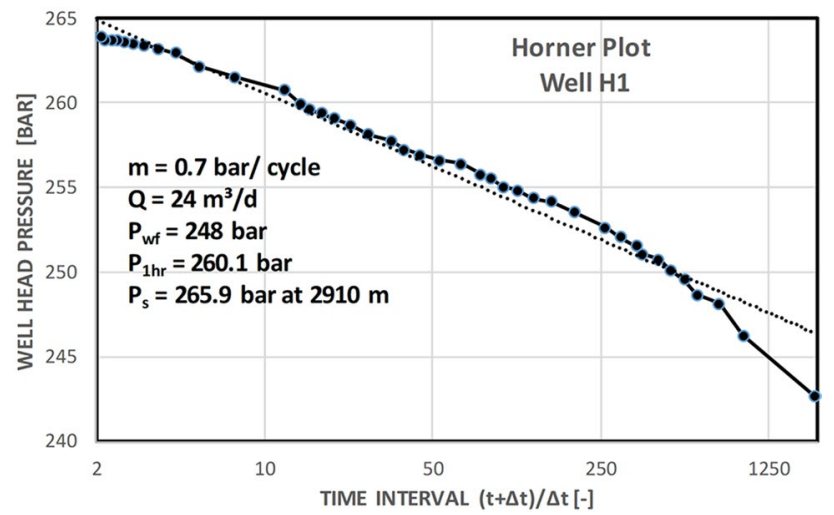

Fig. 5 Horner plot for well candidate $H 1$ in Hummar formation by Amerada tools

228.2 bar for the $\mathrm{S} 1$ well candidate, while well flow pressure recorded a value of 211 bar. This indicates that high pressure exists at the beginning of the well flow, and after $1 \mathrm{~h}$, the well flow pressure decreases. Extensively, this is an indication of existing formation damage in the oilproducing reservoirs (Earlougher Jr. 1977; Soare and Bratu 1987; Ahmed 2010; El-Naggar et al. 2014; Yancheng et al. 2017). In such a scenario, the well acidizing process would have potential economic and ecological concerns due to the corrosion control and avoidance of emulsion formation, as well as the achievement of enhanced oil production rates. Whereas, the formation volume factor is recording figures greater than 1 for each individual target wells, due to relatively denser characteristics at the indicated layer's interval with respect to surface conditions. While, each formation thickness is close to the relevant layer's thickness of interest, with the only exception for the investigated well $\mathrm{H} 1$ that records a value of $4 \mathrm{~m}$ for formation thickness, which is different from than the excessive layer's thickness (about $7.5 \mathrm{~m}$ ). This facet can be attributed to the existence of irregular and isolated seals between the oil-producing structures even in the same layer; similar findings were previously presented by Chang et al. (2008), Morsy et al. (2013), and Al-Mahasneh (2020). Despite the inclusion of acid additives in relatively small volumes, a considerably increase was observed in the well production rates after performing the acid job, with respect to those rates before the execution of the acid job. The reported oil production rates are as follows: from 24 to $145 \mathrm{~m}^{3} / \mathrm{d}$ for well candidate $H 1,30-200 \mathrm{~m}^{3} / \mathrm{d}$ for $S 1,56-62 \mathrm{~m}^{3} / \mathrm{d}$ for $H 2$, and from 20 to $103 \mathrm{~m}^{3} / \mathrm{d}$ for $S 2$. The oil production rates have been accentuated with the factors of 6.0, 6.7, 1.1 , and 5.1 for $H 1, S 1, H 2$, and $S 2$, respectively, indicating a successful matrix acidizing approach for all the target wells. In addition, the total compressibility was found to increase with layer depth with the same formation. By paying attention to the recorded decrease in the dynamic viscosity for the produced oil from $S 2$, relating to $S 1$, this is explained due to higher water saturation of the lower layer of Shueib reservoir with respect to the upper layer. As such, heterogeneous features (irregular thickness, water saturation, and variance in basin' structure) might affect the data collected for different depths and might alter the physical properties even within the same reservoir (Tang et al. 2002; Ahmed 2010; Yuan et al. 2015).

The results for comparing the prediction of skin magnitude by the proposed and reference models are presented in Fig. 6 for the target well candidates. The results represent a consistency in the calculated skin magnitude by the proposed and reference models. The positive skin magnitude values are an indication that the poor connection between
Table 2 Reservoir' performance parameters for the investigated well candidates

\begin{tabular}{|c|c|c|c|c|c|c|c|c|c|}
\hline \multirow[t]{3}{*}{ Parameter } & \multirow{3}{*}{$\begin{array}{l}\text { Formation } \\
\text { Depth [m] } \\
\text { Unit }\end{array}$} & \multirow{2}{*}{\multicolumn{2}{|c|}{$\frac{\text { Hummar }}{2931-2938.5}$}} & \multirow{2}{*}{\multicolumn{2}{|c|}{$\frac{\text { Shueib }}{2889-2898}$}} & \multirow{2}{*}{\multicolumn{2}{|c|}{$\frac{\text { Hummar }}{2912.3-2919.5}$}} & \multirow{2}{*}{\multicolumn{2}{|c|}{$\frac{\text { Shueib }}{2871-2882}$}} \\
\hline & & & & & & & & & \\
\hline & & H1 & $\mathrm{H} 1^{\mathrm{a}}$ & $\mathrm{S} 1$ & $\mathrm{~S} 1^{\mathrm{a}}$ & $\mathrm{H} 2$ & $\mathrm{H} 2^{\mathrm{a}}$ & S2 & $\mathrm{S} 2^{\mathrm{a}}$ \\
\hline$P_{1 \mathrm{hr}}$ & [bar] & 260.1 & 258.4 & 228.2 & 259.9 & 260.7 & 260.1 & 240.8 & 258.0 \\
\hline$P_{\mathrm{wf}}$ & [bar] & 248.0 & 248.0 & 210.9 & 250.3 & 236.5 & 248.3 & 228.0 & 253.5 \\
\hline$P \mathrm{~s}$ & [bar] & 265.9 & 265.9 & 262.2 & 262.2 & 264.2 & 264.2 & 260.6 & 260.6 \\
\hline$m$ & [bar/cycle] & 16.0 & 98.0 & 30.0 & 38.0 & 47.0 & 52.0 & 44.0 & 64.0 \\
\hline$Q$ & {$\left[\mathrm{~m}^{3} / \mathrm{d}\right]$} & 24.0 & 145.0 & 30.0 & 200.0 & 56.0 & 62.0 & 20.0 & 103.4 \\
\hline$B$ & {$[-]$} & 1.06 & 1.08 & 1.11 & 1.11 & 1.06 & 1.08 & 1.14 & 1.14 \\
\hline$\Phi$ & {$[-]$} & 0.12 & 0.12 & 0.15 & 0.15 & 0.11 & 0.11 & 0.11 & 0.11 \\
\hline$c_{\mathrm{t}}$ & {$\left[\mathrm{bar}^{-1}\right] \times 10^{4}$} & 8.82 & 8.82 & 0.65 & 1.42 & 0.91 & 1.47 & 0.56 & 0.86 \\
\hline$r_{\mathrm{w}}$ & {$[\mathrm{m}]$} & 0.11 & 0.11 & 0.11 & 0.11 & 0.11 & 0.11 & 0.11 & 0.11 \\
\hline$H$ & [m] & 4.0 & 4.0 & 9.0 & 9.0 & 7.0 & 7.0 & 11.5 & 10.0 \\
\hline$\mu$ & [mPa.s] & 3.0 & 3.0 & 1.8 & 1.8 & 2.8 & 3.0 & 2.5 & 2.5 \\
\hline
\end{tabular}

${ }^{a}$ Comma refers to target well candidate post-matrix acidizing approach 
the well and reservoir could be attributed to insufficient or limited perforations, some mud invasion, or partial penetration. On the other hand, positive values for the skin magnitude could represent an opportunity to increase the production rate. The well is treated such that new perforations, by means of the matrix acidizing approach, would reduce the skin magnitude and improve the oil-producing area toward the wellbore zone. After acidizing, negative values for skin magnitudes are obtained. In specific, the skin magnitude's expectations by the proposed model for candidate well $\mathrm{H} 1$ decreased from 3.1 to -7.5 ; for $S 1$, from 3.3 to -7.2 ; for $H 2$, from 2.4 to -8.3 ; and for $S 2$, from 2.8 to -6.9 . Various deviations are obtained in comparison with the reference model, but at least the same trend was observed in skin magnitude behavior pre-acidizing approach. This could be attributed to alternation in the well geometry as well the physical characteristics upon stimulation completion, which had enhanced the creation of new wormholes or fissures in the reservoir. The injected acid volumes were approved to be sufficient by gradually lessening the skin magnitude and enhancing the physical properties of the formation (Rabbani et al. 2018). The proposed model depicts an apparent consistency with the reported ranges of skin magnitude found in the relevant literature and is well qualified for predicting skin magnitude.

For appealing the role of the acidizing approach, the skin pressure drop's behavior is focused on. An attainable skin

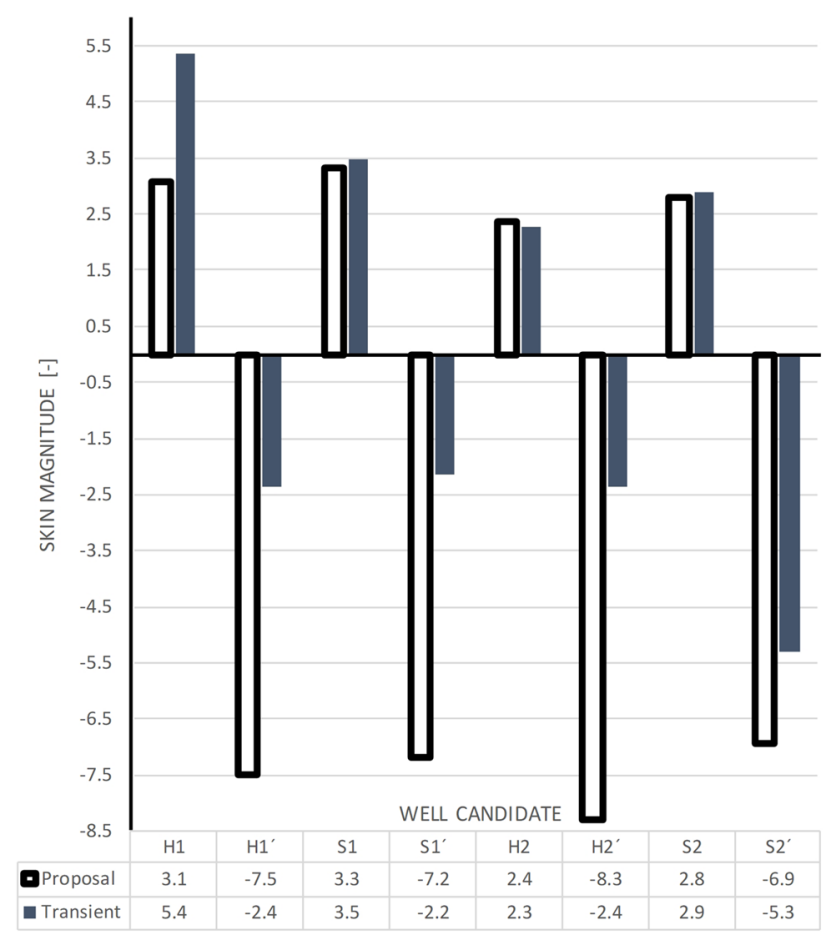

Fig. 6 Skin magnitudes' predictions by proposal and reference models pressure drop will indicate a significant damage magnitude; eventually, oil flow restrictions are present between the wellbore zone and the reservoir. Figure 7 shows the analytical skin pressure drop and the (PI) for the investigated well candidates before and after the acidizing approach. Apparently, there is an enhancement in well performance after the acidizing approach was applied. The reduction in skin magnitude, associated with a decrease in the calculated skin pressure drop post the acidizing approach, is attributed due to the increase in oil inflow into the wellbore zone. In detail, the skin pressure drop for candidate well $\mathrm{H} 1$ was 9.7 to -9.5 bar; for $S 1$, was 19.2 to -2.2 bar; for $\mathrm{H} 2$, was 26.4 to -8.6 bar; and for $S 2$, was 26.4 to -3.1 bar. On the other hand, the (PI) has been enhanced for $\mathrm{H} 1$ going from 1.3 to $8.1\left[\mathrm{~m}^{3} / \mathrm{bar}\right.$. d]; for $S 1$, from 0.6 to 16.9 [ $\mathrm{m}^{3} / \mathrm{bar}$. d]; for $\mathrm{H} 2$, from 2.0 to $3.9\left[\mathrm{~m}^{3} / \mathrm{bar}\right.$. d]; and for $S 2$, from 0.6 to $14.5\left[\mathrm{~m}^{3} /\right.$ bar. d]. Since $\left(\Delta P_{\text {skin }}\right)$ is not a very convenient feature, the (PI) is characterized for the formation's degree of connectivity between the wellbore zone and the reservoir. Positive $\left(\Delta P_{\text {skin }}\right)$ values are mainly obtained in the pre-acidizing job, while negative $\left(\Delta P_{\text {skin }}\right)$ values are achieved for the postacidizing for all target wells. This is explained by the accumulation on the existing perforations by fine particles-even plugging them due to gas hydrates - asphaltene deposits, and rock debris. Besides the attained increase in (PI), it could be revealed that the damage effect is cured by the pre-acidizing approach, due to the sequential cleaning-up of the perforations in the reservoir's matrix. The reported analytical results are consistent with the general trend of enhancement of well performance pre-acidizing approach.

The assessment of the treated wells toward the acidizing job is also highlighted through the findings of the well $\left(r_{d}\right)$ and (FE) for the investigated well candidates, as shown in Fig. 8. A decrease is generally obtained for the $\left(r_{d}\right)$ upon stimulation completion in comparison with the $\left(r_{d}\right)$ prior to acidizing. Explicitly, the $\left(\mathrm{r}_{\mathrm{d}}\right)$ for candidate well $\mathrm{H} 1$ decreased from $2.5 \mathrm{~m}$; for $S 1$, from $3.1 \mathrm{~m}$; for $H 2$, from $1.2 \mathrm{~m}$; and for $S 2$, from 1.9 to $0.1 \mathrm{~m}$, respectively. The estimations of the $\left(r_{d}\right)$ for pre-acidizing approach, Eq. (10), have almost achieved the same dimensions as those of the wellbore radius. In other words, this decrease in the damage effect implies an enhancement of radius extension of the oil-producing area in the reservoirs, which is attributed to negative figures for skin magnitude of the well formation's pre-acidizing approach. These findings synchronize a considerable increase in (FE) for the target well candidates upon stimulation completion. Clearly, the (FE) for candidate well $\mathrm{H} 1$ has been enhanced from 0.4 to 1.3 ; for $S 1$, from 0.6 to 1.2 ; for $\mathrm{H} 2$, from 0.0 to 1.5 ; and for $\mathrm{S} 2$, from 0.4 to 1.4 within the allowable reaction time intervals. The $\left(r_{\mathrm{d}}\right)$ records a few meters for all investigated reservoirs post the acidizing approach; this is consistent with the findings of Soare and Bratu (1987) and Civan (2007). Apparently, this 
is additional evidence for the accomplishment of the matrix acidizing approach of the target wells, such that the acid job of the investigated wells has contributed to the elimination of fine solids and debris from the perforations of the damaged formation.

The (DR) and the (DF) are depicted in Fig. 9 for the investigated well candidates before and after performing acid jobs. A significant decrease is achieved for the parameters of the (DR) and the (DF) after the execution of the acidizing approach. Definitely, the (DR) for candidate well H1 decreased from 1.8 to 0.6 ; for $\mathrm{S} 1$, from 2.9 to 0.5 ; for $\mathrm{H} 2$, from 1.0 to 0.5 ; and for $S 2$, from 1.8 to 0.2 . In turn, the (DF) for candidate well $\mathrm{H} 1$ decreased from 0.6 to -0.3 ; for $\mathrm{S} 1$, from 0.4 to -0.2 ; for $\mathrm{H} 2$, from 1.0 to -0.5 ; and for $\mathrm{S} 2$, from 0.6 to -0.4 . Generally, it is to emphasize the authenticity of the matrix acidizing approach with regards to stimulation of target wells, as well the proper correspondence of the proposed model for predicting the skin magnitudes. Due to the reducing $\left(\Delta \mathrm{P}_{\text {skin }}\right)$ values for the damaged formation, better production rates are achieved after performing the acid treatments.

Similar findings are highlighted in Fig. 10, which represents the (SRs) and the (SG) for the investigated well candidates. Pointedly, the (SR) based on (PI) for candidate well $\mathrm{H} 1$ has increased from 0 to 6.0 ; for $\mathrm{S} 1$, to 28.9 ; for $\mathrm{H} 2$, to 1.9; and for $\mathrm{S} 2$, to 23.7, whereas the (SR) based on $(Q)$ for candidate well $\mathrm{H} 1$ has increased from 0 to 6.0 ; for $\mathrm{S} 1$, to 6.7; for $\mathrm{H} 2$, to 1.1; and for, $\mathrm{S} 2$ to 5.2. Categorically, the (SG) for candidate well $\mathrm{H} 1$ has increased from 0 to $121.0 \mathrm{~m}^{3} / \mathrm{d}$; for $\mathrm{S} 1$, to $170.0 \mathrm{~m}^{3} / \mathrm{d}$; for $\mathrm{H} 2$, to $6.0 \mathrm{~m}^{3} / \mathrm{d}$; and for $\mathrm{S} 2$, to $83.4 \mathrm{~m}^{3} / \mathrm{d}$. The obtained positive values for the (SG) after the acidizing treatments indicate that better production rates

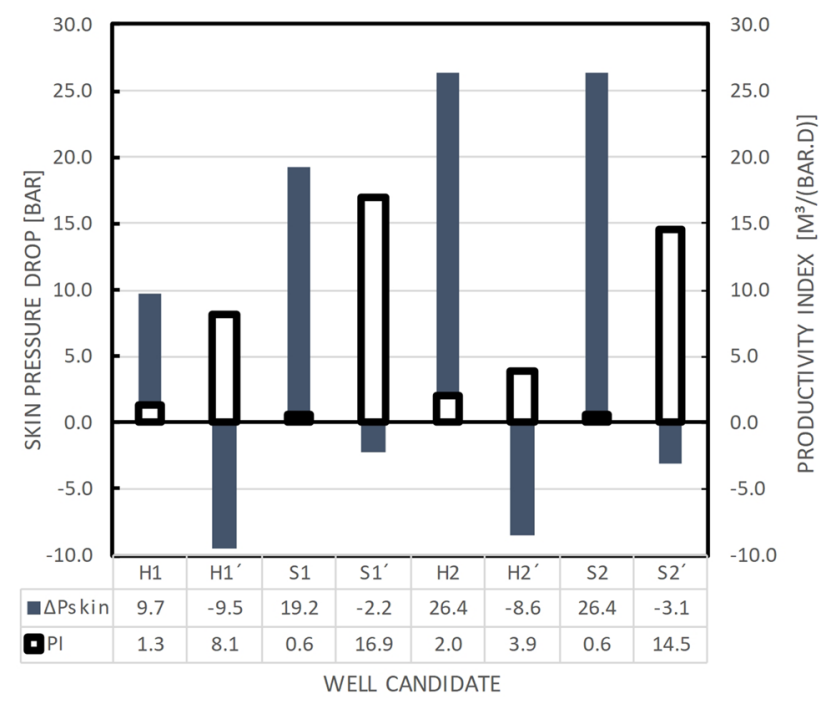

Fig. 7 Skin pressure drop and productivity index for the investigated well candidates are achieved in comparison with those of the pre-job oil flow rates. Positive (SRs) based on (PIs) and (Qs) are promising criteria for estimating the success of the acid treatment. The values of the (SR) based on (PIs) and (Qs) were not identical, since oil production rates are affected by pressure drawdown and the productivity indices are not.

Inspirational results are obtained for the (SR) of the postjob (PI) with respect to the pre-job (PI) in the case of the Shueib and Hummar formations. This is attributed to the geological structure of dolomite for Shueib' target well candidates (S1 and S2). The main effluents of the acid stimulation of a dolomite matrix are the precipitated calcium chloride, the aqueous solution of magnesium chloride, and the gaseous carbon dioxides, as presented by Eq. (2). Hence, the hydrostatic pressure in the wellbore increases due to the relatively higher density of the resulting salt solution. Since $\left(\Delta P_{\text {skin }}\right)$ is the driving force for the oil migration from an undamaged to the damaged zone, the (SR), based on (PIs) as in Eq. (14), might be a more acceptable alternative for estimating the success of the acid treatment in case of a dolomite matrix. This facet is consistent with the findings by Civan (2007), Ifeanyi et al. (2015), and Tiab and Donaldson (2016). However, almost identical values for the (SR), based on $(Q s)$, have been attained for Hummar in relation to those of the Shueib formation. Here, the geological settings of the Hummar formation are mainly composed of the limestone matrix. Referring to Eq. (1), the effluents of the post-job acidizing of limestone rocks are mainly the precipitated calcium chloride and water. Hence, the water drive is the dominant mechanism for oil migration in the investigated Hummar's target reservoirs $(\mathrm{H} 1$ and $\mathrm{H} 2)$. It could be concluded that the (SR), based on ( $Q \mathrm{~s})$ Eq. (15), might be a more acceptable alternative for assessing the success of the acid treatment in the case of the limestone matrix.

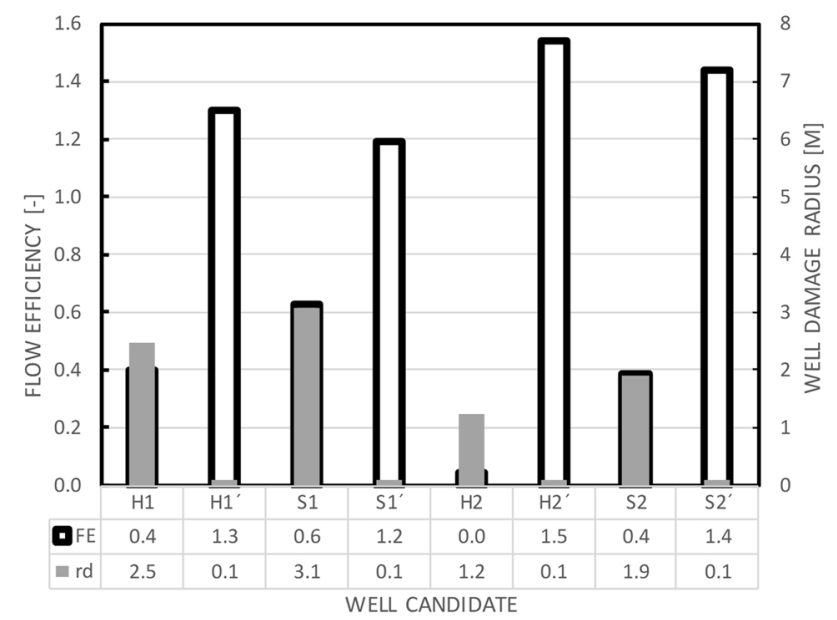

Fig. 8 Flow efficiency and well damage radius for the investigated well candidates

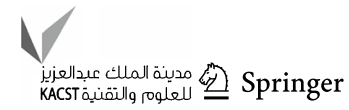




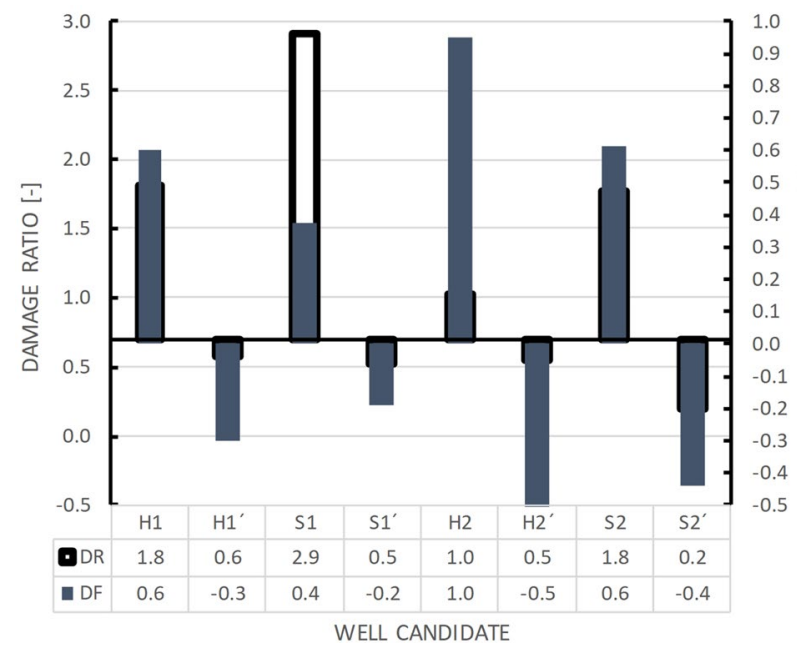

Fig. 9 Damage ratios and factors for the investigated well candidates

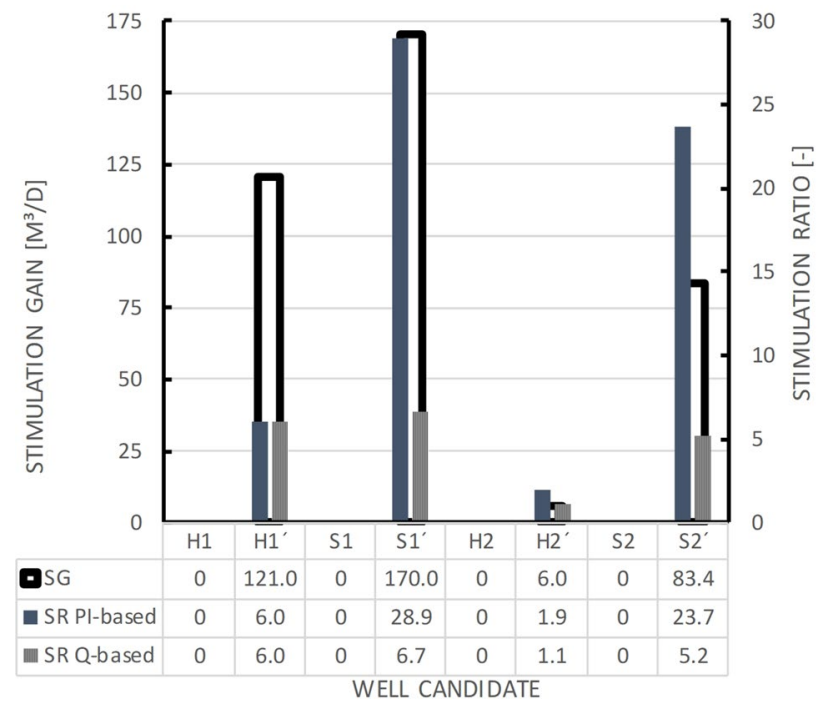

Fig. 10 Stimulation gain and ratios for all investigated well candidates

Generally, a positive response toward matrix acidizing was achieved through a cure treatment of the existing damage in the investigated formations, in spite of the various structures around the wellbore; hence, promising oil productivity from the treated wells is to be expected.

Based on these envisioned results, the development of new investments and the project visualization of relevant oil technology in the Azraq region are prospectively recommended, which would have great influences on the improvement of the socio-economic relations and the infrastructure of the rural region in the area. Additionally, the implementation of the matrix acidizing approach merits further investigations in combination with other oil recovery technologies under high-temperature operations, such as aquathermolysis, for reservoirs including heavy hydrocarbon fractions. Eventually, detailed investigations to conceptualize the formation damage with horizontal orientation are highly recommended.

\section{Conclusion}

By virtue of the matrix acidizing approach, the investigated wells of diverse geological settings have shown a promising response with respect to $(S)$ reduction. Removal of fine particles and debris from formations of limestone and dolomite through the matrix acidizing process could progressively increase oil productivity. Thanks to predefined mixtures of special chemical agents and acid additives, the curing of the formation damage has improved, thus reducing the $(S)$ and enabling the removal of the flow limitations of the oil-producing area toward the wellbore zone of the reservoir. Well stimulation has successfully contributed in the assessment of the oil-producing reservoirs through the achievement of negative figures for $(S)$ and $\left(\Delta P_{\text {skin }}\right)$, as well as advancements in (FE) and (SG). Depending on the investigated geological settings and the operational conditions, the $\left(r_{\mathrm{d}}\right)$ was eliminated, and the oil production rates were enhanced upon well stimulation completion. Furthermore, a semi-analytical model for predicting the skin magnitude was proposed. It has revealed consistent results in comparison with the reference model's expectations from the literature. The inclusion of the reservoir's physical parameters as well the hydrostatic depth properly estimates, to a sufficient degree of extrapolation, the skin magnitude for vertical oil wells with diverse configurations or realistic formation damages.

Acknowledgements Special thanks for the support awarded by AlBalqa Applied University in the conduction of this research work.

Funding Provision of chemicals and field possibilities for sampling, measurements analysis, and coverage of field studiesrelevant costs.

\section{Declarations}

Conflict of interest On behalf of all the co-authors, the corresponding author states that there is no conflict of interest.

Open Access This article is licensed under a Creative Commons Attribution 4.0 International License, which permits use, sharing, adaptation, distribution and reproduction in any medium or format, as long as you give appropriate credit to the original author(s) and the source, provide a link to the Creative Commons licence, and indicate if changes were made. The images or other third party material in this article are included in the article's Creative Commons licence, unless indicated otherwise in a credit line to the material. If material is not included in the article's Creative Commons licence and your intended use is not permitted by statutory regulation or exceeds the permitted use, you will 
need to obtain permission directly from the copyright holder. To view a copy of this licence, visit http://creativecommons.org/licenses/by/4.0/.

\section{References}

Ahmed T (2010) Reservoir engineering handbook, 4th edn. Gulf Professional Publishing, ISBN: 978-1-85617-803-7

Al-Mahasneh MA, Banihani F, Hailat M (2018) Extraction of oil from Jordanian carbonate rock. Am J Oil Chem Technol 6:21-30

Al-Mahasneh MA (2020) Toe-to-heel air injection in-situ combustion process: case study from the Azraq Basin Jordan. RudarskoGeološko-Naftni Zbornik 35(3):77-84

Bale A, Smith M B, Klein H (2010) Stimulation of carbonates combining acid fracturing with Proppant (CAPF): A revolutionary approach for enhancement of sustained fracture conductivity and effective fracture half-length, SPE Annual Technical Conference and Exhibition

Chang FF, Nasr-El-Din HA, Lindvig T, Qui X (2008) Matrix acidizing of carbonate reservoirs using organic acids and mixture of $\mathrm{HCl}$ and organic acids, SPE Annual Technical Conference and Exhibition

Chukwuma NG, Clifford M (2019) Numerical evaluation of formation damage models for application in Niger Delta oil reservoirs. Int J Adv Eng Res Sci 6(5):136-149

Civan F (2007) Reservoir formation damage: fundamentals, modeling, assessment and mitigation. Gulf professional Publishing, Boston

Earlougher RC (1977) Advances in well test analysis, SPE Monograph Series, 5, ISBN: 978-0-89520-204-8

El-Naggar AY, El-Fady EM, Mustafa YM, Ebiad MA, Ibrahim ES (2014) Petroleum in view of its classification, assay and analysis, International Science Congress Association, ISBN: 978-93-84648-05-3

Garrouch AA, Jennings AR (2017) A contemporary approach to carbonate matrix acidizing. J Petrol Sci Eng 158:129-143

Ifeanyi O, Temitope O, Jeffrey O (2015) Effect of matrix acidizing on the performance of selected Niger Delta reservoirs. Int J Oil, Gas Coal Eng 3(2): 18-23

Khalil R, Emadi H, Altawati F (2021) Investigating the effect of matrix acidizing injection pressure on carbonate-rich Marcellus shale core samples: an experimental study. J Petroleum Explor Prod 11:725-734

Kolin SK, Kurevija T, Grebenar D (2018) Pressure build-up test analysis of the hydrocarbon reservoir system with the multiphase flow. Rudarsko-Geološko-Naftni Zbornik. https://doi.org/10.17794/rgn. 2018.3.8

Kurevija T, Strpić K, Kolin KS (2018) Applying petroleum the pressure buildup well test procedure on thermal response test-a novel method for analyzing temperature recovery period. Energies 11(2):366. https://doi.org/10.3390/en 11020366

Leong VH, Mahmud HB (2019) A preliminary screening and characterization of suitable acids for sandstone matrix acidizing technique: a comprehensive review. J Petroleum Explor Prod Technol 9:753-778

Li N, Dai J, Liu P, Luo Z, Zhao L (2015) Experimental study on influencing factors of acid-fracturing effect for carbonate reservoirs. Petroleum 1(2):146-153
Liang T, Gu F, Yao E, Zhang L, Yang K, Liu G, Zhou F (2017) Formation Damage due to Drilling and Fracturing Fluids and Its Solution for Tight Naturally Fractured Sandstone Reservoirs. J Geofluids. https://doi.org/10.1155/2017/9350967

Morsy S, Sheng JJ, Hetherington CJ, Soliman MY, Ezewu RO (2013) Impact of matrix acidizing on shale formation, SPE Nigeria Annual International Conference and Exhibition

Patton BJ, Pitts F, Goeres T, Hertfelder G (2003) Matrix acidizing case studies for the Point Arguello Field, SPE Western regional/ AAPG pacific section joint meeting

Qteishat A, AL-Mahasneh MA (2018) Hydrocarbons potential in the Azraq area. Open J Geol 8(8):753-763

Rabbani E, Davarpanah A, Memariani M (2018) An experimental study of acidizing operation performances on the wellbore productivity index enhancement. J Petroleum Explor Prod Technol 8:1243-1253

Shafiq MU, Mahmud HB (2016) Sandstone matrix acidizing knowledge and future development. J Petroleum Explor Prod Technol $7: 1205-1216$

Soare A, Bratu C (1987) Cercetarea hidrodinamica a zacamintelor de hidrocarburi, Editura Tehnica

Tang Y, Yildiz T, Ozkan E, Kelkar M (2002) Effects of Formation Damage and High Velocity Flow on the Productivity of Perforated Horizontal Wells. SPE-77534-MS. https://doi.org/10.2118/ 77534-MS

Thomas RL, Nasr-El-Din HA, Mehta S, Hilab V, Lynn JD (2002) The impact of $\mathrm{HCl}$ to $\mathrm{HF}$ ratio on hydrated Silica formation during the acidizing of a high temperature sandstone gas reservoir in Saudi Arabia, SPE Annual Technical Conference and Exhibition

Tiab D, Donaldson EC (2016) Petrophysics: theory and practice of measuring reservoir rock and fluid transport properties. Gulf Professional Publishing

Ugbenyen BO, Ogbe DO, Osisanya SO (2011) Efficient methodology for stimulation candidate selection and well workover optimization, Nigeria Annual International Conference and Exhibition

Wilfred CO, Umeleuma MB (2015) Evaluation of A systematic approach to matrix acidizing on an oil producing well. Int $\mathbf{J}$ Res Eng Technol 4(6):219-224

Yancheng L, Xianbo L, Kai K, Tingli L, Shuhong J, Jun Z, Zhang Z, Yunting L (2017) Permeability characterization and directional wells initial productivity prediction in the continental multilayer sandstone reservoirs: a case from Penglai 19-3 oil field Bohai Bay Basin. Petroleum Explor Develop 44(1):97-104

Yuan L, Li XP, Tan XH, Zhang LH (2015) Study on skin factor and Productivity of horizontal well after Acidizing with non-uniform damage. J Chem. https://doi.org/10.1155/2015/706312

Zhang M, Fan J, Zhang Y, Liu Y (2020) Study on the relationship between the water cutting rate and the remaining oil saturation of the reservoir by using the index percolating saturation formula with variable coefficients. J Petrol Explor Prod Technol 10:3649-3661

Publisher's Note Springer Nature remains neutral with regard to jurisdictional claims in published maps and institutional affiliations. 